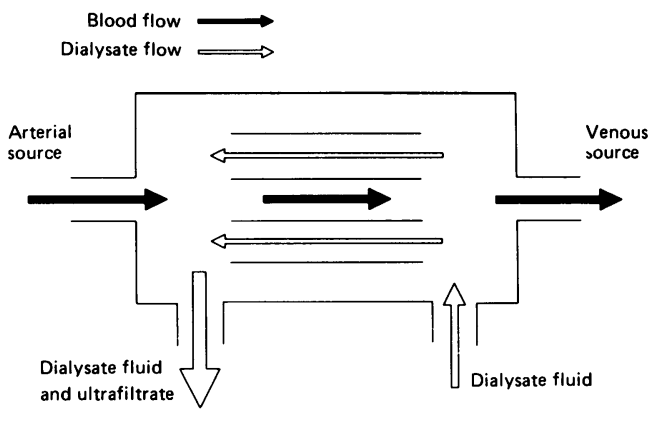

Figure 2 Diagrammatic representation of a haemofilter as used for continuous arteriovenous haemodiafiltration.

current through the haemofilter (fig 2). This achieves a twofold increase in urea clearance. ${ }^{4}$ The use of a dialysis solution with a sodium concentration less than that of the plasma being dialysed would theoretically increase sodium clearance compared with that achieved with haemofiltration alone, although no relevant studies have been reported. Thus it removes sodium by the convective transport of haemofil- tration plus the diffusive transport of haemodialysis. The rate of fall in plasma sodium concentration is regulated by judicious selection of the sodium concentration of dialysate, and maintenance and replacement fluids.

In our experience, it is a simple and safe technique, which does not require specifically trained personnel. A controlled, slow, fall in plasma sodium concentration with adequate removal of fluid was achieved. No complications were associated with its use, and it is a useful alternative in the management of hypernatraemia, particularly in the presence of renal failure.

We thank Dr J Broomhall for his permission to report this patient.

1 Finberg L. Hypernatremic (hypertonic) dehydration in infants. $N$ Engl f Med 1973;289:196-8.

Miller NL, Finberg L. Peritoneal dialysis for salt poisoning. $N$ Engl f Med 1960;263:1347-50.

3 Lieberman KV. Continuous arteriovenous hemofiltration in children. Pediatric Nephrology 1987;1:330-8.

4 Zobel G, Ring E, Trop M, Stein JI. Arteriovenous hemodiafiltration in children. Int $\mathcal{F}$ Pediatr Nephrol 1986;7: 203-6.

\title{
Cardiopulmonary bypass for resection of low tracheal haemangioma
}

\author{
R Franks, M Rothera
}

Department of Cardiothoracic Surgery, Royal Liverpool Children's Hospital R Franks

Ear, Nose, and Throat Department, Royal Manchester Children's Hospital M Rothera

Correspondence to: Mr R Franks, Mr R Franks, Cardiothoracic Unit, Royal Liverpool Children's Hospital Alder Hey, Alder Hey, Liverpool L12 2AP. Accepted 25 January 1990

\begin{abstract}
A 3 month old girl, weighing $4000 \mathrm{~g}$, presented with a capillary haemangioma obstructing the lower trachea and left main bronchus; it was not responsive to steroids. Using cardiopulmonary bypass to maintain oxygenation the tumour was excised. We are not aware that this technique has been used before for the resection of such an obstructive haemangioma.
\end{abstract}

Capillary haemangiomata are common in preterm infants and usually require no treatment. We report a case where surgical excision of the tumour was needed.

\section{Case report}

A 3 month old girl was admitted to hospital from home with a 10 day history of intermittent stridor and two cyanotic episodes during feeding in the previous 24 hours.

She had been born at a supposed 29 weeks' gestation (birth weight $1430 \mathrm{~g}$ ) and had made excellent progress requiring no artificial ventilation. Feeding was initially by nasogastric tube but orally from 5 weeks of age. A $1 \mathrm{~cm}$ diameter capillary naevus was noted on the left side of the neck.

On admission to hospital after the cyanotic episodes she weighed $4000 \mathrm{~g}$ and looked well; there was no cyanosis. There was minimal biphasic stridor, but no increased respiratory effort was evident.

Under general anaesthetic the epiglottis was noted to be short; the upper trachea was normal but a tumour occupied $75 \%$ of the lumen of the lower trachea just above the carina: this significantly occluded the left main bronchus. The lower limit of the mass was just visible and the right and left bronchi appeared normal beyond. A computed tomogram confirmed the bronchoscopic appearance of a hemispherical mass within the tracheal lumen that was restricted to the mucosa and was enhanced with contrast; all this suggested a haemangioma (see figs 1 and 2).

Recovery from the investigations was straightforward. She was extubated and breathed spontaneously without undue effort. In view of the preceding symptoms and the obvious risk of further airway obstruction treatment was commenced with $30 \mathrm{mg}$ of prednisolone daily.

Initially her condition remained stable but 72 hours later there was a noticeable increase in respiratory effort and a transient rise in carbon dioxide pressure. Bronchoscopy showed some increase in tumour size. Stability returned but 24 hours later, relatively suddenly, her breathing became increasingly obstructed. Topical 

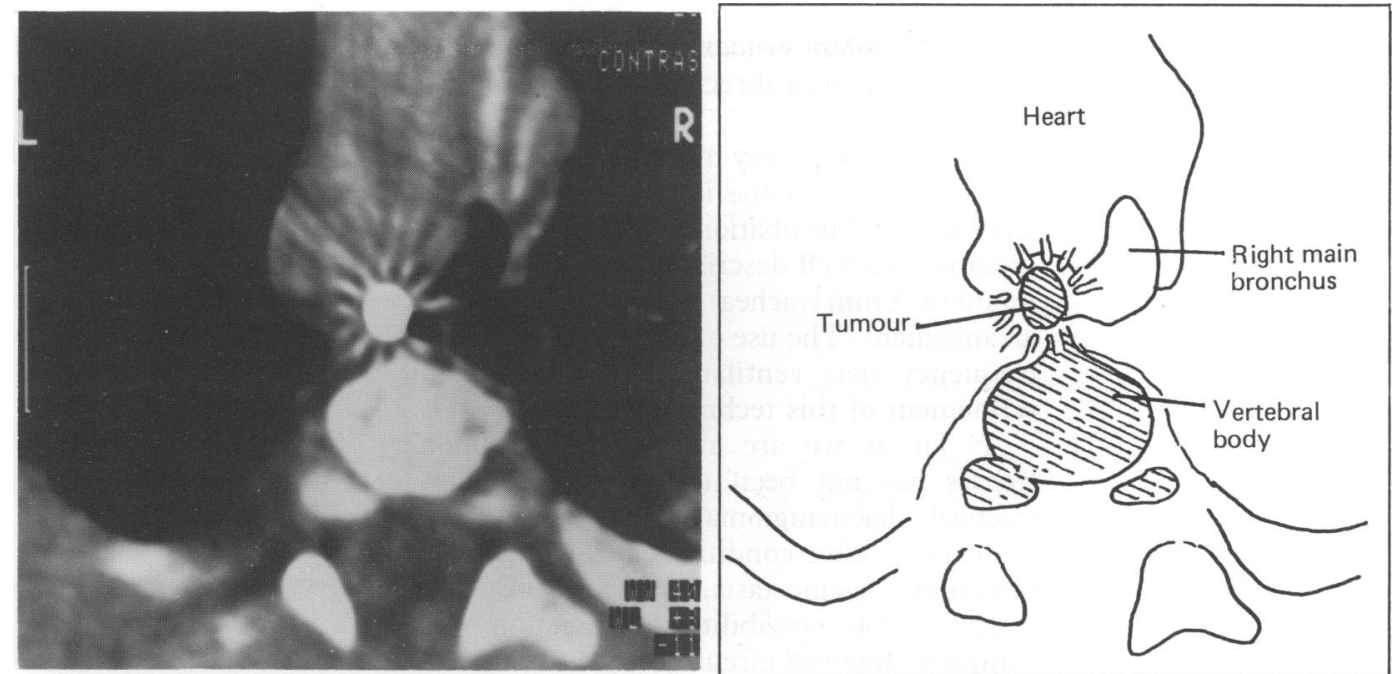

Figure 1 Computed tomogram at the level of the carina, showing a round lesion almost occluding the left main bronchus and enhanced with contrast (surrounded by the 'sunray' artefact).
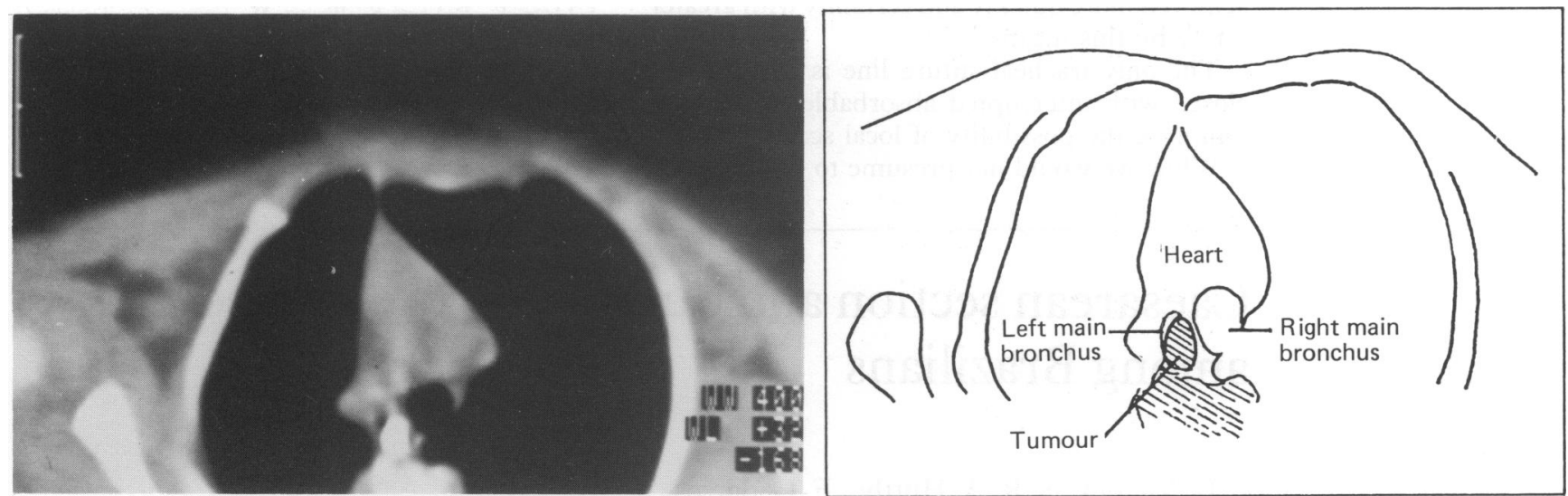

Figure 2 Computed tomogram just below carina clearly showing the right main bronchus and left main bronchus still almost occluded by 'bright' tumour mass.

adrenaline achieved some shrinkage of the tumour but right endobronchial intubation was required to protect the airway.

On normothermic partial cardiopulmonary bypass via mediansternotomy, a $1.5 \mathrm{~cm}$ incision was made in the lower trachea, after withdrawal of the endotracheal (endobronchial) tube. The tumour was excised from the wall and the trachea closed with interrupted $6 / 0$ polydioxanone sutures. The partially collapsed left lung re-expanded and an endotracheal tube was replaced high in the trachea. Postoperative recovery was uneventful. She was extubated 72 hours later after ventilation for 48 hours and continuous positive airway pressure with spontaneous respiration for 24 hours. Histology confirmed the tumour to be a capillary haemangioma.

\section{Discussion}

Capillary haemangiomata are common in preterm infants. Untreated the natural history is of regression with time but this may take anything from six months to three to four years and an initial period of rapid growth is not uncommon. ${ }^{1}$ Large lesions may lead to thrombocytopenia and a consumptive coagulopathy. It was for this that steroid treatment was first used, ${ }^{2}$ but it was subsequently noted to hasten the regression of the lesion in addition to improving platelet function.

Many lesions require no treatment and may be left to follow their natural regression. However, those on the face or obstructing the nose or enlarging to obstruct vision may require intervention. Excision, irradiation, radioactive gold grains, cryotherapy, sclerosants, laser ablation, steroids, and most recently, cyclophosphamide have all been recommended. Scarring remains a problem and steroids represent the most widely used treatment. ${ }^{3}$

Where such haemangiomata occupy the upper trachea, the airway may be protected by tracheostomy or by endotracheal intubation. By such means it may be possible to await the natural regression of these lesions or regression accelerated by steroids. ${ }^{4}$ Even in infancy, such lesions may be amenable to local treatment. The lower trachea is not amenable to this management. The maintenance of the airway in this child was increasingly difficult and even endobronchial intubation $(2.5 \mathrm{~mm}$ endotracheal tube) resulted in considerable practical problems with intermittent selective ventilation of the right lower lobe only.

Endoscopic resection is impractical at this age 
(the Stortz infant bronchoscope is 2.5 to $3.5 \mathrm{~mm}$ diameter). Thus a direct surgical approach was required.

Peroperative airway management represents a major problem in the infant. Direct right and left bronchial intubation by the open trachea is possible and well described, though in a $4000 \mathrm{~g}$ infant (4-5 $\mathrm{mm}$ trachea) would be a cumbersome arrangement. The use of fine catheters and high frequency (jet) ventilation might represent a refinement of this technique.

As far as we are aware, cardiopulmonary bypass has not been utilised for excision of tracheal haemangioma but provided near perfect operative conditions, ${ }^{5}$ allowing accurate resection, haemostasis, and closure of the trachea. The possibility of resection of the complete involved circumference of the trachea had been anticipated and would have been quite feasible. ${ }^{6}$ Good oxygenation and temperature control were provided by cardiopulmonary bypass and it is probable that the operation was achieved more quickly and certainly with greater safety by this means.

The only tracheal suture line is vertical and closed with interrupted absorbable material to minimise the possibility of local scarring.

While we would not presume to question the conventional wisdom of treatment of life or system threatening haemangiomata with steroids, with hindsight in these circumstances we would recommend early rather than later surgical intervention, once it is apparent that there is no benefit from steroids.

We would commend this technique for such procedures in the trachea as providing safe maintenance of oxygenation without the hinderance of tracheal or bronchial intubation.

We are indebted to our colleagues in the dermatology department, in particular Professor C Vickers and Dr J Verbov for providing much background information, and to Mrs S Critchley for typing this manuscript.

1 Amir J, Metzker A, Krikler R, Reisner S. Strawberry hemangiomata in preterm infants. Pediatr Dermatol 1986;3: $331-2$.

2 Frost N, Esterley N. Successful treatment of juvenile hemangiomas with prednisone. $\mathcal{F}$ Pediatr 1968;72:351-7.

3 Edgerton $M$. Treatment of hemangiomas (with special reference to the role of steroid therapy). Ann Surg 1976;183:517-32.

4 Sadan N, Sade J, Grunebaum M. Treatment of subglottic hemangiomas in infants with prednisone. Int $\mathcal{f}$ Pediat hemangiomas in infants with

5 Idriss F, DeLeon S, Ilbawa $M$, Gerson C, Tucker G, Hollinger L. Tracheoplasty with pericardial patch for Hollinger $L$. Tracheoplasty with pericardial patch for
extensive tracheal stenosis in infants and children. $\mathcal{J}$ Thorac

6 Louhimo I, Leijala M. Cardiopulmonary bypass in tracheal surgery in infants and small children. In: Wurnig $P$, ed. Progress in pediatric surgery. Vol 21. Berlin: Springer Verlag, 1987:59-63.

\title{
Caesarean section and duration of breast feeding among Brazilians
}

\author{
C G Victora, S R A Huttly, F C Barros, J P Vaughan
}

\begin{abstract}
A birth cohort study of 4912 Brazilian infants showed that the incidence and duration of breast feeding for children delivered vaginally and for those born by elective caesarean section were similar. Those delivered by emergency caesarean section, however, were not breast fed for as long. This difference persisted after adjustment for confounding variables.
\end{abstract}

Departamento de Medicina Social, Faculdade de Medicina, Universidade Federal Pelotas, CP 464, 96001 Pelotas, RS, Brazil C G Victora S R A Huttly F C Barros

Evaluation and

Planning Centre, London School of Hygiene and Tropical Medicine, London S R A Huttly J P Vaughan

Correspondence to: Dr Victora.

Accepted 9 January 1990

(Arch Dis Child 1990;65:632-4)
Brazil probably has the highest rate of caesarean sections in the world- $31 \cdot 6 \%$ of all babies born in $1981-6$, and $43.2 \%$ of those born in Rio de Janeiro and São Paulo. ${ }^{12}$ If it is true that mothers having caesarean sections are less likely to breast feed, then these appalling rates would be of great consequence not only for perinatal health but also for survival. ${ }^{3-5}$ The associations between the incidence of starting breast feeding and the duration according to the mode of delivery were studied in a Brazilian birth cohort.

\section{Subjects and methods}

The study population comprised 5914 liveborn infants delivered in the city of Pelotas, southern
Brazil, in 1982, which represented over $99 \%$ of all births in the city in that year. ${ }^{6}$ Deliveries were classified as vaginal, elective caesarean section, or presumed emergency caesarean section. Elective caesarean sections are carried out for convenience (scheduled deliveries), because the mother has previously had one, or for tubal ligation (which is illegal in Brazil, but doctors often do caesarean sections to sterilise the mother). Also classified as elective caesarean sections were those in which the first indication (according to the mother) was either prolonged labour or fetal-pelvic disproportion, but in which the second indication was 'repetition' or tubal ligation.

These children were visited again in early 1984, when they were aged between 12 and 27 months. On this occasion mothers were asked whether they had ever breast fed (incidence) and if so, on the duration of breast feeding in months and days.

The analyses were restricted to singleton births, and life table analysis was used to calculate the duration of breast feeding. The odds ratios for being breast fed at the age of 6 months according to the mode of delivery were calculated using logistic regression after adjusting for the following confounding variables: family income, maternal age and education, number of 